\begin{tabular}{l} 
UNES Journal of Community Service \\
UNES \\
$\begin{array}{l}\text { Polume 3, Issue 1, June } 2018 \\
\text { E-ISSN: 2528-5572 } \\
\text { Open Access at: http://lppm.ojc.unespadang.ac.id/index.php/UJCS }\end{array}$ \\
\hline
\end{tabular}

\title{
KETERAMPILAN PEMBUATAN SOUVENIR DENGAN TEKNIK CETAK SABLON UNTUK PEDAGANG KAKI LIMA DI KAWASAN WISATA PANTAI PURUS KOTA PADANG
}

\section{SKILLS OF MAKING SOUVENIR WITH PRINTING PRINTING TECHNIQUES FOR FIVE FEET TRADERS IN PURUS BEACH, PADANG CITY}

\author{
Elida $^{1}$, Budiwirman ${ }^{2}$, Ranggi Rahimul Insan ${ }^{3}$ \\ ${ }^{1}$ Dosen Universitas Negeri Padang \\ E-mail: elidampd@gmail.com \\ 2 Dosen Universitas Negeri Padang \\ ${ }^{3}$ Dosen Universitas Negeri Padang
}

INFO ARTIKEL

Koresponden:

Elida

elidampd@gmail.com

Kata kunci:

keterampilan, mencetak sablon, souvenir.

hal: $23-30$

\section{ABSTRAK}

Pantai Purus merupakan salah satu daerah di Kecamatan Padang Barat Kota Padang yang merupakan daerah wisata pantai yang cukup ramai dikunjungi wisatawan baik dari luar daerah maupun lokal. Mata pencaharian utama masyarakat Pantai Purus sebagian besar adalah nelayan tradisional yang bergantung kepada cuaca dan musim. Pada musim dan cuaca yang baik maka masyarakat purus tersebut akan melaut dan apabila cuaca tidak baik maka mereka tidak pergi melaut, sehingga pendapatan mereka akan berkurang. Selama bertahun-tahun Pantai Purus menyandang gelar daerah yang penduduknya sebagian besar hidup dari melaut yang tergantung kepada cuaca dan musim, padahal sumber daya yang ada cukup memadai. Sebagai daerah pantai dan penduduk yang hanya kebanyakan tamatan SD dan SMP kegiatan para nelayan didaerah tersebut masih dilakukan secara tradisional sehingga penghasilannya tidak banyak. Hasil melaut yang tidak menentu diamping disebabkan oleh musim dan cuaca, ternyata juga disebabkan naik turunnya harga ikan dipasaran. Kadang-kadang ikan banyak, tetapi sering juga tidak mendapatkan hasil yang memadai karena harga dipasar murah atau turun. Oleh sebab itu daerah ini dikatagorikan sebagai daerah yang mempunyai tingkat ekonomi lemah. Pada tahun 2017 tim pengabdian Fakultas Parwisata dan Perhotelan telah melaksanakan kegiatan pada pelaksanaan kegiatan hasil berikut: 1) Pedagang kaki lima dikawasan wisata Pantai Purus kota Padang sangat berpotensi untuk membuat souvenir dengan teknik cetak sablon dan dipasarkan karena daerah merupakan kawasan wisata yang ramai dikunjungi wisatawan; 2). Penyuluhan yang dilakukan dapat meningkatkan pengetahuan pedagang kaki lima masyarakat lokal tentang pembuatan souvenir dengan teknik cetak sablon, 3) Pelatihan dapat meningkatkan keterampilan pedagang kaki lima di kawasan wisata Pantai Purus dalam pembuatan souvenir dengan teknik cetak sablon pada baju kaus dan gantungan kunci yang dapat dipasarkan di kawasan wisata Pantai Purus kota Padang. 


\section{ARTICLE INFO}

Correspondent:

Elida

elidampd@gmail.com

\section{Keywords:}

skills, printing screen printing, souvenirs.

page: 23 - 30

\begin{abstract}
Purus Beach is one of the areas in Padang west Subdistrict, Padang City, which is a beach tourism area that is quite crowded with tourists from outside the region and locally. The main livelihood of Purus Beach community is mostly traditional fishermen who depend on the weather and season. In good weather and whether the Purus community will go to sea and if the weather is not good then they do not go to sea, so their income will decrease. For many years Purus Beach held the title of a region whose inhabitants mostly live from fishing which depends on the weather and the season, whereas the available resources are sufficient. As a coastal area and residents who are only mostly elementary and junior high school graduates, the activities of the fishermen in the area are still done traditionally so that their income is not much. The uncertain results of the sea fishing were caused by the season and weather, it was also due to the ups and downs of fish prices in the market. Sometimes fish are many, but often also do not get adequate results because prices are the cheap or down market. Therefore this area is categorized as an area that has a weak economic level. In 2017 the Faculty of Tourism and Hospitality's dedication team has carried out activities on the implementation of the following results: 1) Street vendors in the tourist area of Purus Beach, Padang city have the potential to make souvenirs with screen printing techniques and marketed because the area is a tourist area that is crowded with tourists; 2). Counseling can improve the knowledge of local street vendors about making souvenirs with screen printing techniques. 3) Training can improve the skills of street vendors in Purus Beach tourism areas in making souvenirs with screen printing techniques on shirts and key chains that can be marketed in Purus Beach tourism area of Padang city.
\end{abstract}

\section{PENDAHULUAN}

Rendahnya tingkat pertumbuhan ekonomi dan investasi menyebabkan rendah pula tingkat kesempatan kerja, yang menyebabkan angka pengangguran dan jumlah penduduk miskin di Sumatera Barat semakin bertambah. Oleh sebab itu perlu dilakukan pembangunan yang terencana dan terarah yang mencakup empat tahapan yaitu perencanaan, pelaksanaan, pengendalian dan evaluasi pembangunan. Keberhasilan pelaksanaan dan pencapaian tujuan pembangunan juga ditentukan oleh kualitas perencanaan pembangunan dengan mangakomodir kebutuhan masyarakat melalui proses perencanaan yang partisipatif. Perda Nomor 5 Tahun 2011 tentang pembangunan adalah Terwujudnya Sumatera Barat madani yang adil, sejahtera.

Sesuai dengan misi, dan agenda RPJMD provinsi Sumatera Barat 2010 -2015: (1).Mewujudkan tata kehidupan yang harmonis, agamais, beradat dan berbudaya berdasarkan falsafah ABS-SBK melalui peningkatan penerapan ajaran agama dan budaya daerah, (2).Mewujudkan tata pemerintahan yang baik, bersih dan professional melalui perbaikan tatakelola pemerintahan daerah, (3).Mewujudkan 
sumberdaya manusia yang cerdas, sehat, beriman dan berkualitas tinggi. Peningkatan Kualitas Sumberdaya Manusia dan Pengembangan IPTEK, (4) Mewujdukan ekonomi masyarakat yang tangguh, produktif, berbasis kerakyatan, berdaya saing regional dan global, melalui pengembangan kegiatan ekonomi dan kesejahteraan masyarakat, dan (5).Mewujudkan pembangunan yang berkelanjutan dan berwawasan lingkungan dengan perbaikan kualitas lingkungan hidup.

Pantai Purus merupakan salah satu daerah di Kecamatan Padang Barat Kota Padang yang merupakan daerah wisata pantai yang cukup ramai dikunjungi wisatawan baik dari luar daerah maupun lokal. Mata pencaharian utama masyarAkat Pantai Purus sebagian besar adalah nelayan tradisional yang bergantung kepada cuaca dan musim. Pada musim dan cuaca yang baik maka masyarakat purus tersebut akan melaut dan apabila cuaca tidak baik maka mereka tidak pergi melaut, sehingga pendapatan mereka akan berkurang.Selama bertahun-tahun Pantai Purus menyandang gelar daerah yang penduduknya sebagian besar hidup dari melaut yang tergantung kepada cuaca dan musim, padahal sumber daya yang ada cukup memadai. Sebagai daerah pantai dan penduduk yang hanya kebanyakan tamatan SD dan SMP kegiatan para nelayan didaerah tersebut masih dilakukan secara tradisional sehingga penghasilannya tidak banyak. Hasil melaut yang tidak menentu diamping disebabkan oleh musim dan cuaca, ternyata juga disebabkan naik turunnya harga ikan dipasaran. Kadang-kadang ikan banyak, tetapi sering juga tidak mendapatkan hasil yang memadai karena harga dipasar murah atau turun. Oleh sebab itu daerah ini dikatagorikan sebagai daerah yang mempunyai tingkat ekonomi lemah.

Pemuda/pemudi di Pantai Purus ini rata-rata untuk mengisi waktunya luangnya hanya ikut bekerja membantu orang tua melaut, dan sebagian ada yang berjualan makanan jajanan disore hari. Dilihat dari tingkat pendidikannya berarti pengetahuan dan pengalamannya masih rendah, sedangkan kesempatan untuk menambah ilmu dan pengetahuan sudah terbatas, apalagi untuk menambah income untuk keluarganya. Berdasarkan pengamatan Tim Pengabdian jurusan IKK FPP UNP, Pantai Purus merupakan daerah yang potensial karena merupakan salah satu pantai wisata yang ramai dikunjungi, sehingga masyarakat nelayan memanfaatkan potensi tersebut untuk melakukan usaha sampingan, suami sebagai nelayan sedangkan istri mereka dengan membuka usaha menjual berbagai makanan dan souvenir. Selama ini terlihat mereka belum ada yang menjual souvenir yang khas di kota Padang. Oleh karena itu dari hasil pengamatan anggota tim kegiatan pengabdian pada masyarakat rasanya perlu peningkatan pengetahuan dan keterampilan para pedagang kaki lima yang ada di Pantai Purus Kecamatan Padang Barat Kota Padang ini terutama dalam hal keterampilan membuat souvenir, karena kita tahu bahwa pedagang kecil juga merupakan sumber daya manusia yang potensial. Berbagai jenis keterampilan dapat diberikan sebagai modal untuk berwirausaha. Salah satu keterampilan tersebut adalah keterampilan mencetak berbagai souvenir atau yang lebih popular dengan nama cetak-mencetak (cetak sablon). Dipilihnya jenis keterampilan ini karena relatif mudah dipelajari, bahan mentah tersedia berlimpah serta tingkat keberhasilan usaha lebih besar.

Teknik cetak screen printing/ cetak sablon paling sederhana dilakukan dengan cara melobangi sebagai pola, terutama untuk mencetak motif, gambar, atau huruf sederhana. Meski pun teknik ini sampai sekarang masih dipakai untuk mengerjakan berbagai keperluan, namun cara tersebut terbatas pada objek (gambar dan huruf) 
dengan motif kasar serta jumlah cetakan yang relatif kecil (Hendarto, 1985). Setelah ditemukannya obat afdruk, yang dipergunakan pada teknik cetak screen printing, maka teknik melobangi sudah banyak ditinggalkan. Hal tersebut disebabkan karena berbagai kemudahan dan keuntungan yang didapatkan dari teknik cetak screen printing. Cetak screen printing dengan mempergunakan obat afdruk lebih efektif dan efisien. Jumlah cetakan yang lebih banyak dengan waktu pengerjaan lebih sedikit, kualitas cetakan lebih baik, dapat mencetak pada hampir segala permukaan bidang, pengerjaannya yang tidak terlalu sulit, dan memerlukan biaya relatif kecil. Oleh karena itu, kecenderungan penggunaan cetak screen printing dengan memanfaatkan obat afdruk makin memasyarakat. Penggunaannya bukan hanya untuk keperluan karya seni, tetapi juga dalam industri modern yang bersifat komersil (Rachbini, 1979), dengan demikian, cetak screen printing dapat dijadikan sebagai suatu usaha yang potensial untuk menghasilkan uang (Basir, 1986). Bahkan cetak screen printing telah diajarkan di sekolah yang ditandai dengan tercantumnya materi cetak pada Kurikulum SMP, SMK, dan SMA. Cetak screen printing tidak menuntut keterampilan tinggi, tidak menuntut ruangan besar atau studio khusus. Bahan-bahan yang digunakan relatif mudah didapat, karena banyak diperjualbelikan di pasaran bebas (lihat proses cetak screen printing pada lampiran gambaran teknologi yang akan diterapkembangkan). Murahnya biaya produksi disebabkan karena sebagian besar peralatan yang digunakan dapat dimanfaatkan secara berulang-ulang, serta pemakaian bahan yang tidak begitu banyak.

Masyarakat khususnya pemuda/pemudi perlu dibekali dengan berbagai pengetahuan dan keterampilan dibidang pengolahan makanan jajanan yang sehat, dan pembuatan souvenir agar mampu mandiri. Adanya keterampilan dan pengetahuan yang dimiliki memberikan peluang kepada masyarakat untuk membuka usaha baru yang sekaligus merekrut tenaga kerja yang pada akhirnya dapat membantu pemerintah mengurangi pengangguran.Berdasarkan permasalahan tersebut, maka dirasa perlu untuk memberikan pengetahuan dan keterampilan kepada pedagang kecil di Pantai Purus tersebut, khususnya keterampilan membuat berbagai jenis souvenir khas kota Padang, agar mereka dapat memanfaatkan waktu luangnya dengan baik yang akhinya dapat dijadikan suatu usaha rumah tangga, yang dapat meningkat ekonomi keluarga keluarga. Target yang dicapai dari kegiatan pengabdian kepada masyarakat ini adalah:

1. Khalayak sasaran diberikan pengetahuan dan keterampilan terkait proses screen printing/ cetak sablon yang dapat dipergunakan sebagai modal wirausaha.

2. Khalayak sasaran difasilitasi mengaplikasikan teknik screen printing/ cetak sablon dengan menggunakan media cetak dari monil.untuk membuat souvenir berupa gantungan kunci dan baju kaus.

\section{METODE PELAKSANAAN}

\section{Waktu, Tempat, dan Peserta Kegiatan}

Kegiatan ini dilakukan di kelurahan Purus kecamatan Padang Barat Kota Padang, dilaksankan pada bulan September tahun 2017. Peserta kegiatan ini adalah masyarakat di kelurahan Purus kecamatan Padang Barat Kota Padang sebanyak 15 orang.

\section{Metode Pelaksanaan}


Supaya tujuan pengabdian masyarakat ini tercapai dengan maksimal, maka dalam memberikan pelatihan digunakan metode yang bervariasi, yaitu:

1. Metode ceramah dan tanya jawab untuk memperkenalkan pengetahuan dan keterampilan yang diberikan. Metode demonstrasi diberikan dalam proses mencetak sablon. Kepada peserta pelatihan akan didemonstrasikan bagaimana alat yang digunakan, bahan yang digunakan dalam membuat sablon, membuat desaian sablon, memindahkan desaian pada monil, proses pengeringan, proses pencetakan.

2. Metode pemberian tugas yang diberikan kepada peserta setelah pelatihan. Tugas dapat dikerjakan di rumah masing-masing, berdasarkan desain yang dibuat masing masing dan yang sudah di sempurnakan oleh instruktur dan tugas dibuat sesuai dengan teknik yang diberikan.

Pada waktu pemberian teori peserta akan ditempatkan dalam satu kelas, semua peserta dapat mengikuti ceramah dan demontarsi dari intruktur. Untuk praktek peserta di bagi menjadi dua grup, setiap grup dibimbing oleh dua orang instruktur.

\section{HASIL KEGIATAN}

Kegiatan pengabdian masyarakat ini dilaksanakan 3 hari sesuai dengan kesempatan dari masyarakat Kelurahan Purus Kota Padang tersebut yaitu Sabtu dan Minggu tanggal 16, 23 dan 24 September 2017. Kegiatan berlangsung dari jam 10.00 pagi sampai jam 17.00 sore. Pelaksanaan kegiatan dilakukan non stop artinya secara terus, bagi yang ada keperluan dapat dilakukan sesuai dengan kepentingannya, misalnya sholat, kecuali makan siang dilakukan bersama-sama. Peserta kegiatan adalah pemuda putus sekolah kelurahan Purus kecamatan Padang Barat Kota Padang. Peserta kegiatan yang diharapkan adalah sebanyak 15 orang. Pada saat kegiatan yang hadir sebanyak 15 orang, karena peserta pada umum adalah masyarakat sekitar dekat dengan kantor lurah tempat dilaksanakan kegiatan.

Pengetahuan dan keterampilan yang diberikan dilaksanakan dengan metode ceramah dan yaitu metode demonstrasi yang dilaksanakan secara rinci adalah sebagai berikut:

1. Menjelaskan tentang teknik mencetak sablón, bahan dan alat yang digunakan melalui metode ceramah,

2. Menerangkan cara mencetak sablón pada baju kaus dan membuat gantungan kunci,

3. Mendemonstrasikan bagaimana teknik cetak sablón, mendesain, memindahkan desaian, mengeringkan, dan mencetak pada baju kaus dan Gantungan kunci,

4. Metode drill atau latihan yang diberikan kepada peserta, serta diiringi dengan bimbingan mulai dari cara mendesain gambar pada plastic, memindahkan, meletakan desaian di atas kain, dan mencetak,

5. Metode pemberian tugas yang diberikan kepada peserta setelah pelatihan. Tugas dapat dikerjakan di rumah masing-masing, berdasarkan desain yang dibuat masing masing dan yang sudah di sempurnakan oleh instruktur dan tugas dibuat sesuai dengan teknik yang diberikan adapun langkah-langkah pelaksanaan dapat dilihat pada gambar berikut. 

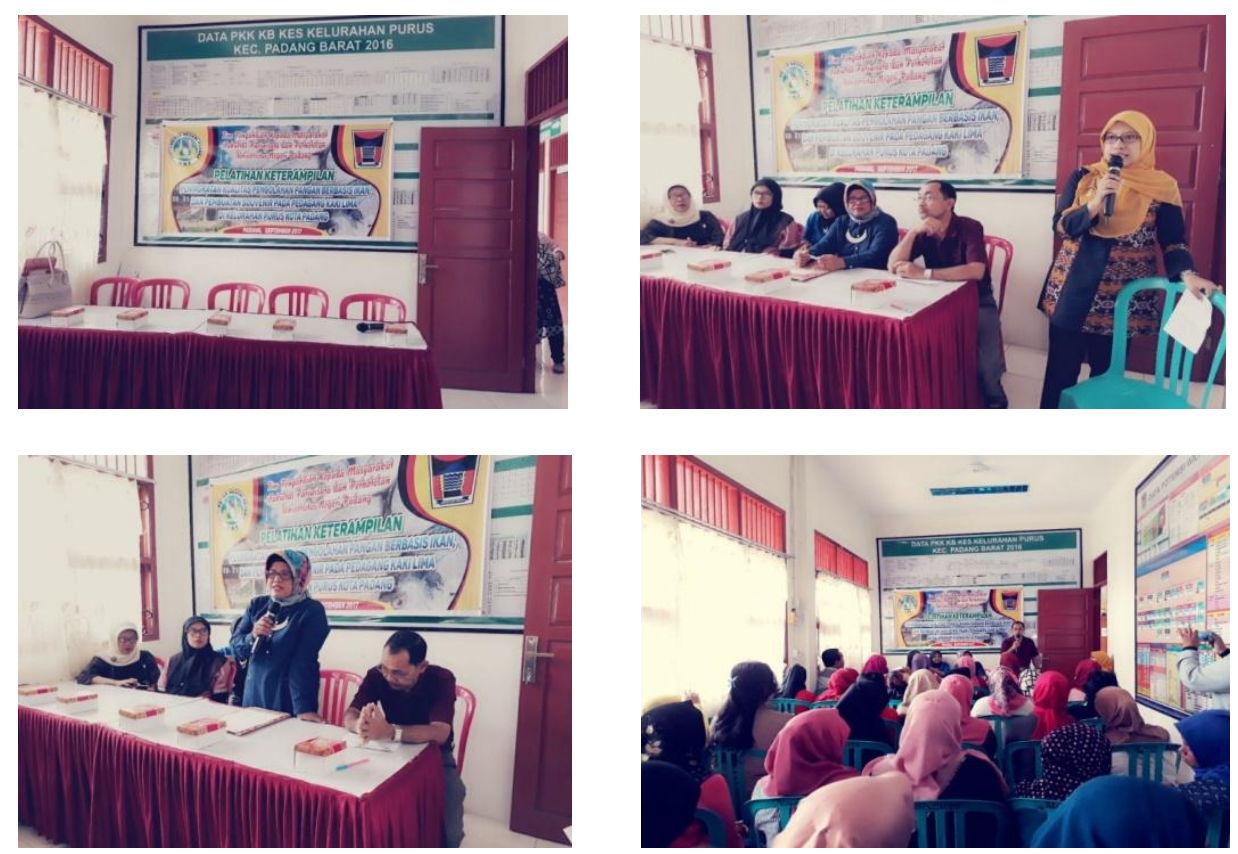

Gambar 1. Acara Pembukaan Pelaksanaan Pengabdian
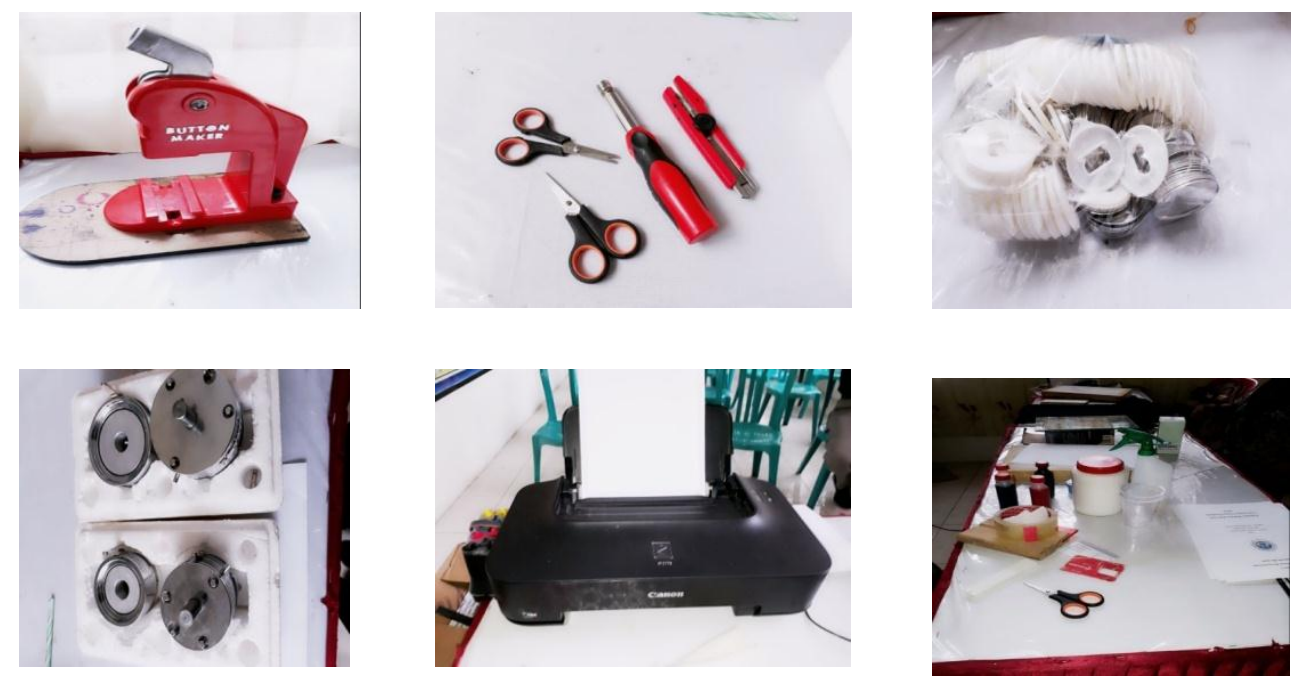

Gambar 2. Alat dan Bahan Pembuatan Souvenir dan Sablon
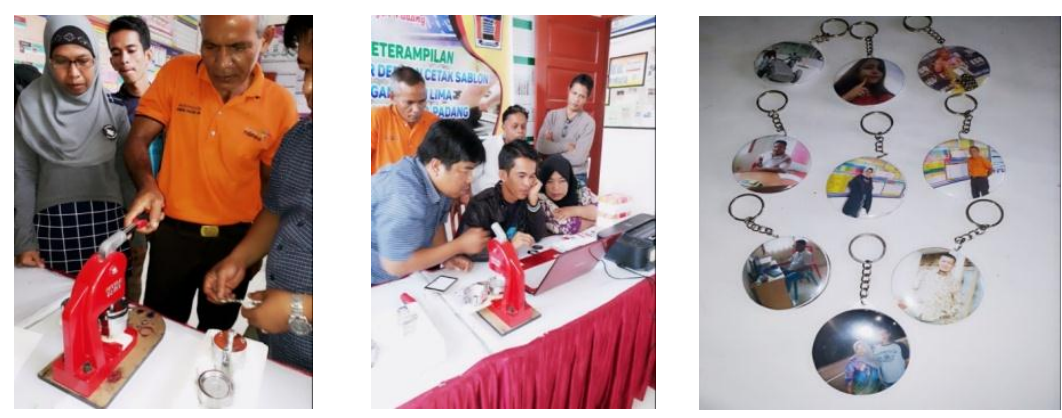

Gambar 3. Teknik Pembuatan Souvenir Gantungan Kunci 

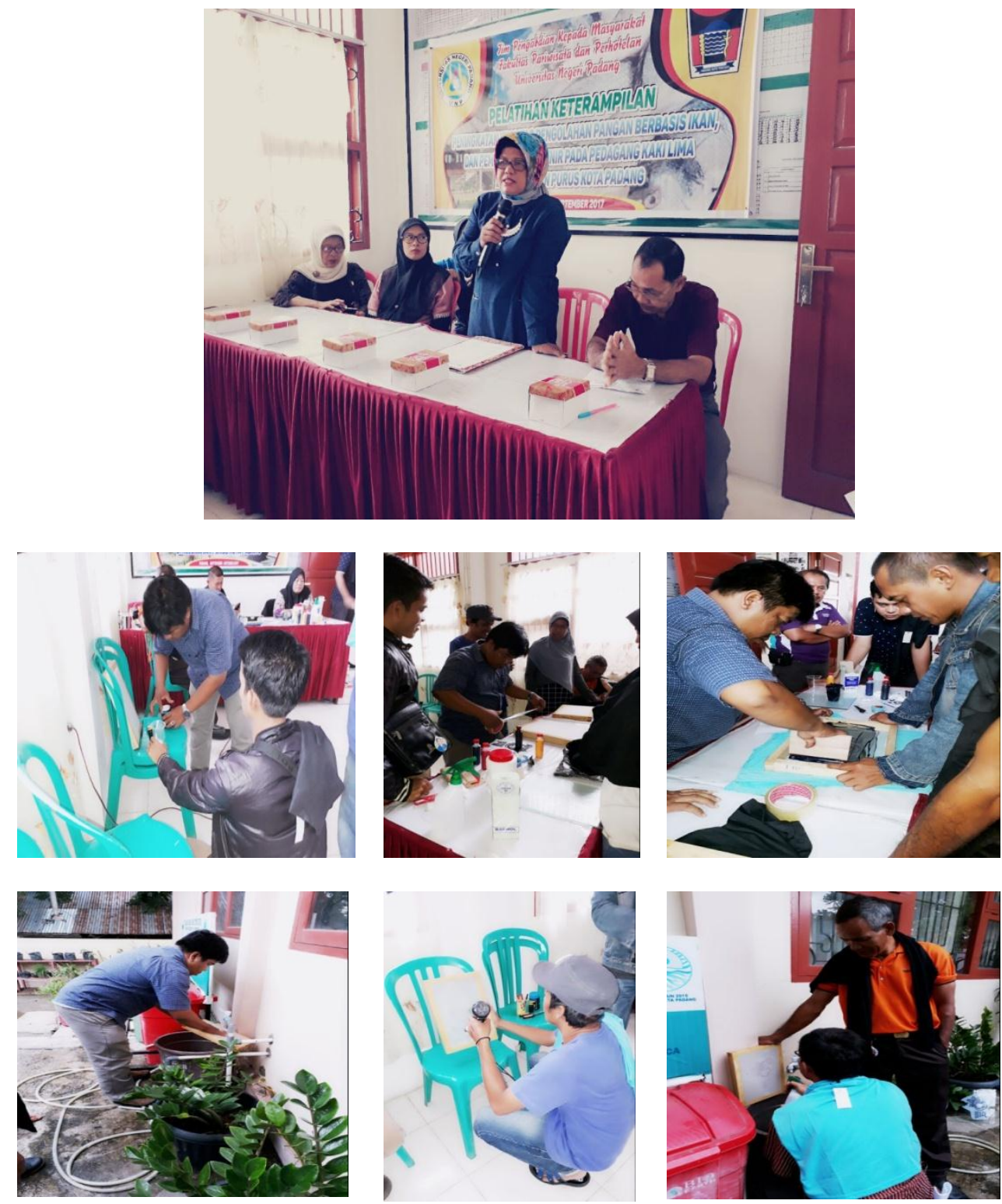

Gambar 4 Teknik Pembuatan Souvenir Baju Kaus

Pada waktu pemberian teori peserta akan ditempatkan dalam satu kelas, semua peserta dapat mengikuti ceramah dan demontarsi dari intruktur. Untuk praktek peserta di bagi menjadi dua grup, setiap grup dibimbing oleh dua orang instruktur. Pada kelas praktek peserta diarahkan untuk berlatih membuat desain dan membuat pola dengan terlebih dahulu kepada masing-masing peserta dibagikan kertas dan pensil untuk mendesain. Instruktur membimbing dan membentu menyempurnakan desain yang sudah dibuat oleh peserta pelatihan. Desain yang sudah dianggapap baik lalu dicetak.

Dengan mendapatkan pengetahuan dan keterampilan ini, ternyata pemuda putus sekolah Kelurahan Purus selama kegiatan pelatihan dilakukan hamper semua peserta dapat mengikuti dengan baik dan sungguh-sungguh. Pada umumnya kegiatan berjalan lancer dan baik, selama dilaksanakan tetapi walaupun demikian ada juga sedikit faktor-faktor penghambat seperti peserta yang datangnya tidak tepat waktu, banyak peserta yang belum mempunyai keterampilan dasar me sehincetak sehingga perlu bimbingan yang sangat ekstra dari instruktur dan tim pengabdian apalagi peserta terdiri dari tingkatan pendidikan dan umur yang bervariasi. 


\section{SIMPULAN DAN SARAN}

\section{Simpulan}

Setelah pelaksanaan kegiatan ini dapat disimpulkan sebagai berikut :Peserta sudah memahami tentang cetak sablon, produk cetak sablon., bahan dan alat yang digunakan untuk mencetak sablon.dan peserta telah memiliki keterampilan mendesain pola cetak sablon untuk baju kaus. dan gantungan kunci.

\section{Saran}

1. Perlu tindak lanjut dari lembaga terkait di pemerintah untuk selalu memfasilitasi pengembangan objek wisata.

2. Diperlukan pendampingan dalam hal menjalin kerjasama satu lembaga dengan yang lain.

3. Perlu pemantauan dan evaluasi.

\section{DAFTAR PUSTAKA}

Ebdi E. Sajiman. 2005. Dasar-Dasar Tata Rupa \& Desain (Nirmana). Jokyakarta: Arti Bumi Intaran

Heskett, John. 1986. Desain Industri. Jakarta: CV. Rajawali.

Mei Hidayat, 2003. Kreasi patchwork dan quilting. Jakarta: Puspa Swara.

Meiko Simamora, 1997. Seni Patchwork dan quilting, Jakarta: Pt. Gramedia Pustaka Utama.

Pulukadang, Warsia Rusbani. 1982. Keterampilan menghias kain. Bandung: Angkasa.

Sachari, Agus. Tth. Desain Produk Sebuah Pengantar. Bandung: ITB.

Tn, 2006. Panduan pengelolaan hibah penelitian, pengabdian kepada masyarakat. Jakarta: Direktorat Penelitian dan Pengabdian Kepada Masyarakat.

UU Otonomi Daerah No.22 tahun 1999. 